\title{
Evolución normativa y jurisprudencial de la edad de retiro forzoso en Colombia y la garantía del mínimo vital del servidor público*
}

\author{
Regulatory and jurisprudential evolution of the age of forced retirement in \\ Colombia and the guarantee of the vital minimum of the public servant
}

Fernando Antonio Moreno González**

Fecha de recepción: 15 de febrero de 2018

Fecha de aprobación: 10 de abril de 2018

\section{RESUMEN}

Los cargos públicos no son ocupados a perpetuidad, ya sea por períodos fijos, faltas disciplinarias que derivan en destitución, o por cumplimiento de la edad de retiro forzoso, siendo esta última, fundamento del objeto de estudio de esta investigación. De este modo, es importante conocer la legalidad de la edad de retiro forzoso consagrada en el ordenamiento jurídico colombiano y su interpretación y aplicabilidad en el escenario jurídico práctico. No obstante, existe un inconveniente respecto de algunos servidores públicos a los cuales les es aplicable la causal de retiro forzoso por cumplimiento de edad, pero esta transgrede su derecho fundamental al mínimo vital, sobre todo cuando no hay una concreción de su derecho pensional, representado en el reconocimiento y pago de la prestación económica correspondiente. De ahí que se cuestione si la aplicación de la edad de retiro forzoso como causal de desvinculación del servicio debe aplicarse dentro de la rigurosidad de la ley o modulada por la garantía del

* Artículo producto del proyecto de investigación: "Evolución normativa y jurisprudencial de la edad de retiro forzoso en Colombia y la garantía del mínimo vital del servidor público”, realizado en el marco del programa de la Especialización en Derecho de Trabajo en la Universidad de Buenos Aires, Argentina. DOI: http://dx.doi. org/10.15332/s1909-0528.2018.0002.06

** Abogado, estudiante del Doctorado en la Universidad de Buenos Aires UBA, Buenos Aires, Argentina, con maestría en Derecho Penal y Criminología y en Derecho Administrativo. Universidad Libre, Bogotá D. C., Colombia. Correo electrónico: fernandoantoniomorenogonzalez@gmail.com 
mínimo vital del servidor que pretende ser retirado. Así, con el propósito de establecer resultados propios del método científico y abrir un espacio al debate, surgido de la comprensión del lector, se desarrolló el método histórico-lógico de la investigación, que permitió determinar el desarrollo histórico del objeto de estudio e identificar jurídicamente los avances y retrocesos en la materia, teniendo clara cuenta del transcurso normativo y jurisprudencial sobre la edad como causal de retiro del servicio y de la importancia del derecho al mínimo vital del servidor público que se desvinculará.

Palabras clave: edad de retiro forzoso, mínimo vital, función pública, empleo público.

\section{Abstract}

The government jobs are not occupied for life, because the fixed periods, the disciplinary offences that lead to impose a dismissal, or reaching the forced retirement age, the latter being the basis of the research's subject matter. In this way, it is important to know the legality of the forced retirement age, enshrined in the Colombian law and her interpretation and implementation in the legal scene. However, there is a problem concerning to many public employees, in the implementation of the forced retirement age, but this violates their fundamental right of a living wage, especially when there is not a realization of theirs pension or retirement rights, through the recognition and payment of the pertinent economic benefit. Therefore, it asks if the implementation of the forced retirement age, like a disassociation causal of the public service must be implemented within stringent legislation or be adaptive by the guarantee of the living wage of the public employees waiting to be retired. Thus, in order to set results of the scientific method, and open a scene of discussion, as of the lector's comprehension, it has been developed the historical-logical method of the research, that help to determinate the historical develop of the research's subject matter, and the identification of the legal progress and setbacks, considering the course of the laws and the jurisprudence about the forced retirement age and the importance of the living wage of the public employees waiting to be retired.

Keywords: the forced retirement age, the living wage, the public service, the government jobs. 


\section{INTRODUCCIÓN}

Atendiendo a la dinámica de la función pública en Colombia, se tiene el hecho de que los cargos públicos no pueden ser ocupados a perpetuidad, ya sea a causa de períodos fijos, de faltas disciplinarias que ameritan la destitución o en virtud del cumplimiento de cierta edad, que se configura como de retiro forzoso, siendo esta última el pilar de estudio de esta investigación. De este modo, es importante conocer la legalidad de la edad de retiro forzoso, plenamente consagrada en el ordenamiento jurídico colombiano y su interpretación y aplicabilidad en el escenario jurídico práctico; se determina así, como objeto de la presente investigación, el análisis de la configuración de la causal de retiro por edad y si este debe aplicarse de forma rigurosa o a través de la protección de derechos fundamentales que gozan de garantía constitucional y convencional ${ }^{1}$.

No obstante, se presenta un inconveniente entre un grupo de servidores públicos ${ }^{2}$, de diversas entidades, a los cuales les es aplicable la causal de retiro forzoso por cumplimiento de la edad, que radica en la transgresión de su derecho fundamental al mínimo vital, sobre todo cuando no hay una concreción absoluta de su derecho pensional, representado en el reconocimiento y pago de la prestación económica de seguridad social correspondiente. Ello se presenta a causa de la desvinculación misma, hecha conforme a la ley, que termina el pago de un salario, pero que determina el desmejoramiento económico absoluto del servidor que aún no puede gozar de su pensión de vejez, indemnización sustitutiva o devolución de saldos ${ }^{3}$.

1 Lo dispuesto supone entender, y siguiendo a Bobbio, "que antes de hablar de una teoría jurídica marxista, de lo que puede hablarse, con cierta rigurosidad, es de una influencia de teorías sociológicas del derecho, derivadas de las referencias aisladas de Marx a lo jurídico" (Castro, 2018, p. 23).

2 Atendiendo a la noción de servidor público, es importante reflexionar lo dispuesto por Herrera (2018), para quien: "Antes de iniciar por saber quién se constituye como sujeto de derechos, es importante decir que el reconocimiento de un ser o una entidad como sujeto de derechos es lo que permite que tal sujeto pueda desarrollarse, tener y ejercer derechos y tenga la capacidad de obligarse, por tanto, de ahí proviene la importancia de determinar quién se constituye como sujeto de derechos y qué significa ser sujeto de derechos" (p. 57).

$3 \mathrm{Al}$ respecto, es importante resaltar que con la expedición de la Carta Política de 1991, se pretendía la protección de todos los ciudadanos, "encauzando su atrevimiento a conseguir que esta desplegara su labor en desarrollar todos los medios posibles para obtener así la intervención de todos sus asociados y contribuir a velar por sus derechos. Pero lo pretendido no obtuvo los resultados esperados en virtud a la cantidad de falencias en la Constitución, por ello todos los asociados continuaron en la búsqueda de sus derechos por la vía judicial, pretendiendo con ello un fallo justo y a su favor" (Suárez y Vallejo, 2017, p. 146). 
De ahí que resulte pertinente plantear un problema acorde a las vicisitudes actuales, a partir del cual se cuestione: ¿La aplicación de la edad de retiro forzoso como causal de desvinculación del servicio debe aplicarse dentro de la rigurosidad de la ley o modulada en virtud de la garantía del mínimo vital del servidor que pretende retirarse del servicio?

El problema planteado es importante debido a la dimensión jurídica que detenta. No se trata de una descripción básica de contenidos legislativos, sino de un análisis de la interpretación de una norma dotada de legalidad, en contraposición con su aplicación en el tiempo y espacio actual, tendientes a la salvaguarda de los derechos humanos.

Asimismo, es importante resaltar el aporte de esta investigación, que se basa en la proporción de una mayor comprensión sobre la dinámica del escenario jurídico, en el que la taxatividad de las leyes no asegura el cumplimiento del fin social del derecho. De este modo, se espera que pueda ser demostrada la prevalencia del derecho fundamental al mínimo vital, sobre el carácter expreso de la norma que consagra la edad de retiro forzoso como causal de desvinculación del servicio.

Ahora bien, a fin de establecer resultados propios de una investigación científica y abrir un espacio al debate, devenido de la comprensión del lector, fue aplicado el método histórico-lógico de la investigación, que será descrito y desarrollado a continuación.

\section{MÉTodo}

Haciendo uso del método histórico-lógico de la investigación, se elaboró un estudio del fenómeno de la edad de retiro forzoso del servicio público en Colombia, analizando su trayectoria histórica y sus manifestaciones concretas a través de la historia.

El uso de este método permitió determinar el desarrollo histórico del objeto de estudio de la presente investigación, además de identificar jurídicamente los avances y retrocesos en la materia, teniendo clara cuenta del factor de necesidad en el transcurso normativo y jurisprudencial sobre la edad como causal de retiro del servicio público. 
En su ejecución, se estableció el devenir histórico en la configuración legislativa e interpretación judicial acerca de la naturaleza y función social de la edad de retiro forzoso, además de su relación directa con diversos principios que atienden a las condiciones particulares de quienes ejercen la función pública. Todo lo cual se realizó en el marco de un sistema de análisis que evitaba caer en elementos especulativos sobre la evolución del fenómeno.

De este modo, se logró sobrepasar una simple definición histórica que carece de valor dentro de un método científico, creando un mecanismo de análisis lógico de la edad de retiro forzoso del servicio público, en contrapeso del principio del mínimo vital que atiende al servidor, como persona humana. Así, fue posible ubicar la dinámica de la investigación en un escenario puramente científico, que abre paso no solo a resultados de índole histórico, sino que plantea una discusión alrededor de la función social del derecho.

\section{Discusión}

Como fundamento esencial se tiene a la Constitución Política de 1991, la cual establece, en su artículo 125, que el retiro del servicio público se efectuará por tres razones principales, a saber: la calificación no satisfactoria en el desempeño, la transgresión al régimen disciplinario, y las demás causales de orden constitucional y legal ${ }^{4}$.

Partiendo de lo anterior, es válido recordar que el legislador goza de una facultad constitucional para crear normas que desarrollan diferentes materias, pero que se sujetan a la prevalencia de la Carta Política, en el marco del principio de la jerarquía de normas. Por ello, es pertinente analizar cuál es la autoridad competente para reglar el tema concreto de la edad de retiro forzoso; pues bien, se evidencia que es una potestad constitucional transferida al legislador. $Y$ es precisamente lo que se ha

4 De conformidad con Suárez (2018), “el art. 123 de la Carta Magna indica que los servidores públicos serán todas aquellas personas que trabajen en organismos estatales independientemente de si son entidades del orden central o descentralizado, así como el siguiente art. establece que la ley determinará la forma de ejercer y el tipo de responsabilidad de los servidores públicos, y el subsiguiente indica que todos los servidores públicos serán de carrera administrativa excepto los de libre nombramiento y remoción así como los de elección popular y los demás que determine la ley" (p. 148). 
venido desarrollando con la facultad extraordinaria otorgada al presidente de la República mediante la Ley 65 de 1967; así fue expedido el Decreto Ley 2400 de 1968, que consagró el criterio de la edad de 65 años como causal de cesación definitiva de la función pública ejercida por los servidores públicos, imposibilitando el reintegro, salvo por aquellos empleos descritos en el inciso 2 del artículo 29 de la misma norma, modificado por el Decreto Ley 3074 de 1968.

El empleado que reúna las condiciones para tener derecho a disfrutar de una pensión de jubilación, cesará definitivamente en sus funciones y será retirado del servicio, dentro de los seis (6) meses siguientes a la fecha en que reúna tales condiciones. No obstante, el Gobierno podrá establecer excepciones para el retiro, cuando las necesidades del servicio lo exijan (Decreto Ley 2400, artículo 29, 1968).

Así las cosas, teniendo en cuenta que, con ocasión a la existencia de un derecho pensional, el servidor no pueda ser reintegrado a su empleo, es válido hacer la aclaración que dicha premisa encuentra su excepción en la necesidad del servicio, siempre que se trate de ocupar los cargos de:

\begin{abstract}
Presidente de la República, ministro del despacho, jefe de departamento administrativo, superintendente, viceministro, secretario general de ministerio o departamento administrativo, presidente, gerente o director de establecimientos públicos o empresas industriales y comerciales del Estado, miembro de misiones diplomáticas no comprendidos en carrera y secretarios privados de los despachos de los funcionarios de que trata este artículo. Por necesidades del servicio, el Gobierno podrá ampliar estas excepciones siempre y cuando no sobrepase la edad de sesenta y cinco (65) años (Decreto Ley 2400, art. 29, 1968).
\end{abstract}

De este modo, a partir de la norma mencionada, es posible llegar a tres conclusiones hasta este punto: primero, que el artículo 29 prohíbe el reintegro a la rama ejecutiva de quienes tengan estatus de pensionados oficiales, salvo los cargos mencionados en su inciso 2; segundo, que el artículo 31 dispone que la edad de retiro forzoso de los empleados de la rama ejecutiva es de 65 ańos, y se prohíbe el reintegro al servicio cuando se haya llegado a dicha edad, salvo los cargos mencionados en el inciso 2 del artículo 29; y tercero, que el mismo artículo 29 faculta al Gobierno para que fije otros cargos que harán parte de la excepción a la prohibición de reintegro de 
pensionados oficiales, pero que no involucra la salvedad respecto de la edad de retiro forzoso.

El literal C del artículo 25, el numeral 5 del artículo 105, y el artículo 120 del Decreto 1950 de 1973, que reglamenta el Decreto Ley 2400 de 1968 y el Decreto Ley 3074 del mismo año, establecen que el ejercicio de un empleo público, en su rama ejecutiva, se determina por el hecho de ser menor de 65 años, salvo por lo dispuesto en sus artículos 121 y 122; ello se debe a que estipula que la edad produce la cesación del ejercicio de funciones públicas, y en consecuencia el retiro (Decreto 1950, 1973, art. 120).

Así que, este decreto dispone la obligación de notificación de este hecho a la entidad nominadora, por parte del empleado. Y aunque, con ocasión a la necesidad del servicio, el Gobierno estará facultado para efectuar el reintegro correspondiente, este deberá tener en cuenta que el empleado no llegare a sobrepasar la edad de 65 años.

Asimismo, este ordenamiento estipula que habrá una edad que determina un impedimento para el desempeño de cargos públicos, cual es la de 75 años; ello sin perjuicio de las excepciones tratadas en el inciso 2 del artículo 29 del Decreto 2400 de 1969, adicionado por el Decreto 3074 de 1969 (Decreto 1950, 1973, art. 122).

Para efectos de tener más conocimiento sobre la excepción contenida en el Decreto 1950 de 1973, se procede a citar el contenido literal del mismo:

\begin{abstract}
La persona retirada con derecho a pensión de jubilación no podrá ser reintegrada al servicio, salvo cuando se trate de ocupar las posiciones de: (1) Presidente de la República; (2) Ministro del despacho o jefe de departamento administrativo; (3) Superintendente; (4) Viceministro o secretario general de ministerio o departamento administrativo; (5) Presidente, gerente o director de establecimiento público o de empresa industrial o comercial del Estado; (6) Miembro de misión diplomática no comprendida en la respectiva carrera; (7) Secretario privado de los despachos de los funcionarios anteriores; (8) Consejero o asesor; y (9) Las demás que por necesidades del servicio determine el Gobierno, siempre que no se sobrepase la edad de los sesenta y cinco (65) años (artículo 121).
\end{abstract}

No obstante, se consideraron otras salvedades en otros cuerpos normativos, como por ejemplo la de ocupar el cargo de director general de unidad administrativa 
especial con o sin personería jurídica, establecida en el Decreto 2040 de 2002; el cargo de subdirector de departamento administrativo, estipulada en el Decreto 4229 de 2004; el cargo de secretario de despacho cód. 020, de las gobernaciones y alcaldías, dispuesto en el Decreto 863 de 2008; el cargo de subdirector o subgerente de establecimiento público, consagrado en el Decreto 740 de 2009; y los cargos de presidente, gerente o subgerente de empresa oficial de servicios públicos del orden nacional o territorial, determinados por el Decreto 3309 de 2009.

Mediante la Sentencia C-351 de 1995, que declaró exequible el artículo 31 del Decreto Ley 2400 de 1968, que ratificó la vigencia del artículo 122 del Decreto 1950 de 1973, y que determinó que la edad de 65 ańos o más constituye impedimento para desempeñar cargos públicos, la Corte Constitucional dispuso que la excepción a la prohibición de reintegro operaría para aquellos servidores de elección popular, para los que se establece un período fijo, como por ejemplo, el presidente y el vicepresidente de la República, los miembros de cuerpos colegiados, congresistas, diputados, concejales, ediles, gobernadores y alcaldes. Ello se debe a la naturaleza misma de su elección, cual fuere la voluntad popular, manifestada en el proceso electoral correspondiente, que le otorgan el derecho y el deber a una persona determinada de cumplir con las disposiciones constitucionales, que, a su vez, no prevén la edad de retiro forzoso para dichos cargos.

La función social de la edad de retiro forzoso, en interpretación de lo dicho por la Corte Constitucional en esta sentencia, reposa en la proporción de oportunidades laborales para las nuevas generaciones, ya que los cargos públicos no pueden ser ejecutados a perpetuidad por un solo servidor; ello en consonancia con la teoría de la institucionalización del poder público, que contempla el ejercicio temporal de la función pública, que a la postre, debe estar dotada de eficiencia y eficacia, por medio de la renovación de los cargos públicos (Sentencia C-351, 9 de agosto de 1995).

Debido a lo anterior, fue válido determinar para la Corte, que el artículo 31 del Decreto Ley 2400 de 1968 no deja en estado de indefensión, ni discrimina, a los mayores de 65 años, ya que estos tienen el derecho constitucional y legal a la pensión por vejez, además, es claro que el Estado debe propender por la garantía de eficiencia de la función pública y por la renovación generacional del servicio. 
A partir de lo expuesto anteriormente, se han suscitado algunas controversias entre la causal de retiro por obtener pensión de vejez y la edad de retiro forzoso. Así, vale la pena resaltar que el artículo 41 de la Ley 909 de 2004, tratando las causales de retiro, dispone que el retiro del servicio de quienes se encuentren desempeñando empleos de libre nombramiento y remoción y de carrera administrativa se produce, entre otras, por la edad de retiro forzoso y por haber obtenido la pensión de jubilación o vejez; artículo que fuera declarado exequible por la Sentencia C-501 de 2005, a través de la cual, la Corte Constitucional aclaró que no se puede dar por terminada la relación laboral sin que se notifique debidamente la inclusión en la nómina de pensionados correspondiente; situación que también se contempla en el parágrafo 3 del artículo 9 de la Ley 797 de 2003, declarado exequible por la Sentencia C-1037 de 2003.

No obstante, en el escenario práctico se presentan algunas situaciones, sobre las cuales es válido plantear un análisis: primero, cuando el servidor posee los requisitos para acceder a la pensión, pero no tiene el reconocimiento y notificación en nómina pensional; segundo, cuando el servidor no posee los requisitos para acceder a la pensión, ni tiene el reconocimiento y notificación en nómina pensional y, tercero, cuando el servidor no posee los requisitos para acceder a la pensión, pero no realiza los trámites para obtener reconocimiento y notificación en nómina pensional.

Si en los anteriores casos opera el retiro forzoso, a pesar de las circunstancias, se configura una transgresión del derecho fundamental del mínimo vital del servidor, quien debería gozar de especial protección constitucional, sumado a que la falta de reconocimiento y pago de la pensión se considera como negligencia de la entidad.

A este respecto, la Corte Constitucional, a través de la Sentencia T-012 de 2009, concluyó que:

La Secretaría de Educación de Bogotá vulneró el derecho fundamental del accionante al mínimo vital, al haberlo retirado del servicio por haber cumplido la edad de retiro forzoso de 65 años, sin haber realizado una valoración de sus circunstancias particulares, que consultara y garantizara la protección de sus derechos fundamentales, y sin haber tenido en cuenta que el demandante había presentado una solicitud de pensión 
que estaba pendiente de decidirse de fondo por la entidad de prestación social correspondiente (p. 2).

De igual forma, la Corte expresó que en virtud de que la administración procedió a la desvinculación del servidor con ocasión al cumplimiento de la edad de retito forzoso, sin hacer una valoración de su dependencia al salario y sus necesidades, y sin considerar el hecho de que no gozaba del derecho pensional por mora imputable a la entidad, se configura una violación injustificada y desproporcionada del derecho fundamental al mínimo vital (Sentencia T-865, 27 de noviembre de 2009).

En el mismo sentido, la Corte Constitucional señaló que al retirar al servidor público sin la garantía de un sustento económico representado en la pensión, como sustituto del salario que dejará de percibir, vulnera sus derechos fundamentales al mínimo vital, a la dignidad humana y a la vida (Sentencia T-007, 14 de enero de 2010).

Igualmente, la Corte sostuvo que antes de que se efectuara la desvinculación del cargo, la entidad — Fiscalía General de la Nación— debió completar la historia laboral del servidor, requerir al ISS, y colaborarle al empleado en el proceso de reconocimiento y pago de la pensión que le asistía, ya que este había notificado previamente a la entidad sobre el cumplimiento de los requisitos para acceder a su derecho prestacional de seguridad social (Sentencia T-487, 16 de junio de 2010).

En el mismo sentido, la Corte profiere la Sentencia T-154 de 2012, a través de la cual dispuso que, en virtud del retiro forzoso de un servidor de 66 años, sujeto de especial protección por razón de su edad, sin consideración de la situación particular del funcionario de pensión no definida, se vulneraron los derechos fundamentales del mínimo vital, la seguridad social, el trabajo y la vida en condiciones dignas:

Si bien, la empresa expuso como el motivo del retiro del servicio del peticionario la causal de haber llegado a la edad de retiro forzoso, debió prever de igual forma el impacto que dicha decisión produciría en sus condiciones de vida digna, pues era el único medio de subsistencia que tenía (p. 14).

Posteriormente, la Corte trató el caso de un funcionario retirado del servicio a causa de su edad superior a 65 años, pero al que no se le había reconocido el derecho a la pensión, a causa de cotizaciones faltantes. A este respecto, se recordó que cuando al 
cotizante le faltaren menos de 3 años para gozar de su derecho pensional, no puede ser desvinculado sino hasta el momento en el que obtenga el mínimo de cotizaciones. Sin embargo, en el caso concreto, al servidor le faltaba el equivalente a 5 años en semanas, por lo que no podía ser considerado como prepensionado, situación por la cual, no podía garantizársele una estabilidad reforzada que lo blindara del retiro (Sentencia T-839, 23 de octubre de 2012).

A su vez, la Corte reitera la necesidad de valorar las condiciones particulares del servidor que es retirado por el hecho de haber llegado a la edad de 65 años, a fin de no recaer en la vulneración de sus derechos fundamentales, sobre todo en el escenario de hacer efectiva la desvinculación del cargo, sin que el servidor cuente materialmente con su derecho pensional, con independencia de si se trata de una pensión de vejez, indemnización sustitutiva o devolución de saldos (Sentencia T-174, 8 de marzo de 2012).

En el mismo sentido, en las Sentencias T-822 de 2014 y T-643 de 2015, la Corte mencionó una subregla construida por la doctrina constitucional, a través de la cual se estableció que la causal de llegar a la edad de retiro forzoso puede ejecutarse solo si se valoran las condiciones particulares del servidor que pretende ser desvinculado, con el fin de evitar una eventual transgresión a los derechos fundamentales a la vida digna y al mínimo vital.

Ahora bien, el Decreto 1083 de 2015, a través del cual se expidió el Decreto Único Reglamentario del Sector de Función Pública, dispuso que, si una persona es retirada del servicio, con derecho a la pensión de jubilación, no podrá obtener reintegro, excepto si fuere a desempeñar los cargos de:

1. Presidente de la República, 2. Ministro del despacho o director del Departamento Administrativo, 3. Superintendente, 4. Viceministro o secretario general de ministerio o departamento administrativo, 5. Presidente, gerente o director de establecimiento público o de empresa industrial o comercial del Estado, 6. Miembro de misión diplomática no comprendida en la respectiva carrera, 7. Secretario privado de los despachos de los empleados anteriores, 8. Consejero o asesor, y 9. Las demás que por necesidades del servicio determine el Gobierno, siempre que no se sobrepase la edad de los sesenta y cinco (65) años. 
La persona que se encuentre gozando de pensión de jubilación y que no haya llegado a la edad de 65 años, podrá ser reintegrada al servicio al empleo de: 1.- Director General de Unidad Administrativa Especial con o sin personería jurídica, 2.- Subdirector de Departamento Administrativo, 3.- Secretario de Despacho código 020, de las Gobernaciones y Alcaldías, 4.- Subdirector o Subgerente de establecimiento público y 5.- Presidente, Gerente o Subgerente de Empresa Oficial de Servicios Públicos del orden nacional o territorial (artículo 2.2.11.1.11).

Por otro lado, la Corte Constitucional profiere la Sentencia T-376 de 2016, mediante la cual manifiesta, en términos literales, que:

\begin{abstract}
Si bien se ha declarado la constitucionalidad de distintas disposiciones que han fijado la edad de retiro forzoso en 65 años, la aplicación de esta causal deber ser razonable, no puede efectuarse de forma automática y siempre debe consultar a la situación particular del servidor público, con el fin de evitar una afectación al mínimo vital (p. 30).
\end{abstract}

De este modo, antes de dar ejecución a la causal de retiro forzoso por edad, la entidad deberá tener la certeza sobre la prestación pensional a la que tiene derecho el servidor que pretende ser retirado, deberá cerciorarse del cumplimiento de todas las cotizaciones exigidas por la ley, y deberá atender al tiempo de cotizaciones que le faltaren. En caso de que dicho servidor pueda gozar de su derecho pensional en menos de 3 años, lo que procederá será su reintegro inmediato al cargo, en tanto esta situación se materialice — con reconocimiento y pago—, o hasta que este opte por la indemnización sustitutiva o devolución de saldos, caso en el cual deberá evidenciarse una colaboración efectiva al servidor en los trámites correspondientes, por parte de la entidad (Sentencia T-376, 15 de julio de 2016).

Finalmente, se encuentra la Ley 1821 de 2016, que deroga expresamente el artículo 31 del Decreto Ley 2400 de 1968 y el artículo 29 del Decreto Nacional 3074 de 1968; tácitamente, los artículos 119 al 124 del Decreto Nacional 1950 de 19735; y que deroga también los Decretos Nacionales, referidos a la facultad otorgada a los notarios para que continúen ejerciendo sus cargos, hasta la edad de 70 años.

5 Debido a que estos artículos tratan el hecho de que resulta imposible el ejercicio de funciones públicas a un servidor que cumpla la edad de 65 ańos. 
Esta Ley trae varias modificaciones al compendio de normas sobre edad de retiro forzoso: se amplía a 70 años el tope de edad para el ejercicio de funciones públicas estatales:

1. La norma aplica a servidores que prestan sus servicios en las ramas del poder público, en los órganos autónomos e independientes — a excepción de las universidades públicas, las corporaciones autónomas, el Banco de la República, y la Comisión Nacional del Servicio Civil—, en los órganos de control, y en las demás entidades o agencias públicas, además de particulares que cumplen funciones como notarios, curadores y miembros de las cámaras de comercio; contempla excepciones a la imposibilidad de ingresar o permanecer en empleos públicos luego de los 70 años (Ley 1821 de 2016);

2. Tiene un campo de aplicación limitado, exceptuando a los servidores de elección popular mencionados en el artículo 260 de la Constitución Política y a quienes ejerzan funciones públicas en prestación ocasional de servicios oficiales, que se denominan auxiliares de la administración pública (Ley $1821 \mathrm{de}$ 2016);

3. Esta norma aplica para los servidores que ingresen o se encuentren en cargos de función pública al momento de su entrada en vigencia, quienes tienen la facultad de decidir si han de permanecer en el servicio público, luego de cumplir con los requisitos para disfrutar de la pensión, hasta la edad de 70 años, claro está, sin llegar a percibir dos asignaciones del Estado — salario y pensión(Ley 1821 de 2016);

4. Los docentes que se rigen por el Decreto 2277 de 1979, y los que fueron vinculados antes de entrar en vigor la Ley 812 de 2003, que gozan de la compatibilidad prestacional entre la pensión de jubilación y su salario, tienen la facultad de seguir en el ejercicio de la docencia, y continuar percibiendo hasta la edad de 70 años. Sin embargo, los docentes que se rigen por el Decreto Ley 1278 de 2002, podrán continuar ejerciendo la docencia, una vez adquieran el derecho a la pensión, hasta los 70 años de edad, pero sin percibir el pago compatible entre salario y pensión (Ley 1821 de 2016); 
5. No obstante, independientemente del régimen, los docentes vinculados a la prestación de la educación estatal, tienen la facultad de ejercer sus funciones públicas hasta la edad de 70 años, siempre que así lo manifiesten por escrito a las Secretarías de Educación, a los Fondos de Prestaciones del Magisterio de cada entidad y a la Fiduciaria Previsora S. A., manifestando su voluntad de permanecer en el cargo de docente oficial, con sujeción a lo dispuesto en esta Ley, además de la autorización al ente territorial respectivo, para que se hagan los descuentos laborales después de haber adquirido el estatus de pensionado (Ley 1821 de 2016);

6. Por último, en el caso de los docentes universitarios, se continuará obedeciendo la disposición del artículo 19 de la Ley 344 de 1996, pero ajustada a la nueva edad de retiro forzoso. Así, estos maestros pueden estar en el ejercicio de sus cargos hasta por 10 años más de la edad de retiro forzoso, es decir, hasta los 80 años (Ley 1821 de 2016).

\section{Resultados}

A partir de la aplicación del método histórico-lógico de la investigación, sobre el objeto de estudio que nos concierne, se obtuvieron resultados de gran trascendencia. En primer lugar, que, a partir del Decreto Ley 2400 de 1968, la edad de retiro forzoso fue establecida en 65 ańos, sin posibilidad de reintegro al servicio; sin embargo, las renovaciones normativas apuntaron a aumentar dicha edad a 70 años, desde la Ley 1821 de 2016.

Ahora bien, teniendo en cuenta el dato numérico, es válido mencionar que la edad de retiro forzoso constituye una causal de retiro de un servidor del ejercicio de la función pública. Y la razón primaria de esto depende de la teoría de la institucionalización de la función pública, que imprime relevancia a la temporalidad de la ocupación de los cargos públicos y el relevo generacional con miras a la garantía de la eficiencia y eficacia de la administración pública.

No obstante, la ejecución de la edad de retiro forzoso como causal de desvinculación de la función pública, no debe ser plena ni ajustarse a la literalidad de la ley. Es 
importante modular su aplicación, tomando en consideración las situaciones particulares del servidor que pretende ser retirado de su cargo con el fin de evitar la transgresión de derechos fundamentales, de protección constitucional primaria, como el mínimo vital, la seguridad social, el trabajo y la vida en condiciones dignas.

De este modo, el método de investigación aplicado permitió evidenciar que existe una obligación de la administración de velar por el servidor que haya alcanzado la edad de retiro forzoso, en su calidad de sujeto con protección o estabilidad reforzada, claro, dependiendo de sus condiciones particulares.

Igualmente, fue posible demostrar que la condición particular más reiterativa dentro de los servidores en edad de retiro forzoso se basa en la falta de concreción del derecho pensional que le pudiere asistir, entendiéndose como reconocimiento y pago de la prestación. Y es precisamente esta eventualidad la que configuraría una excepción en la operación efectiva de esta causal de retiro, ya que no puede desconocerse que el servidor requiere de un mínimo vital, que dejaría de percibir en razón a la desvinculación de su cargo, y de la inexistencia material de una pensión, indemnización sustitutiva o devolución de saldos.

Así las cosas, resulta de vital importancia concluir que la causal legal de retiro, que se estudia en esta investigación, opera siempre que se tengan en cuenta las condiciones particulares de los sujetos a quienes se les aplica, en garantía de los derechos fundamentales, de protección constitucional y convencional. De esta manera, uno de los derechos con mayor protección en el ejercicio de la función pública es el mínimo vital, que, aunque entra en una ponderación lógica con la legalidad misma, se ubica en un escenario en el que es necesario infringir esta última, con ocasión a su satisfacción.

Finalmente, pero sin restar importancia, fue posible poner de presente diversas excepciones a la regla legal general de edad de retiro forzoso como causal de retiro, devenidas de criterios jurídicos lógicos, facultades otorgadas o prerrogativas concedidas. Es el caso de los funcionarios públicos de período fijo sometidos a la soberanía del pueblo a través de la elección popular, los de libre nombramiento y remoción, los notarios, y los docentes oficiales y universitarios que están vinculados al sistema de educación estatal colombiano. 


\section{Conclusiones}

Con ocasión al hallazgo de los resultados anteriormente expuestos, es importante validar la hipótesis planteada al inicio de la investigación, a fin de estructurar un debate jurídico acerca de la aplicación efectiva de la edad de retiro forzoso como causal de desvinculación del servicio, en consonancia con la garantía del derecho fundamental al mínimo vital.

De este modo, se demuestra que la hipótesis se valida, ya que, según disposiciones reiterativas en la jurisprudencia de la Corte Constitucional, la causal de desvinculación por edad de retiro forzoso, que actualmente versa en 70 años, debe modularse, sujetándose a la observancia del derecho fundamental del mínimo vital, determinado por la consideración de las condiciones del servidor público sobre el cual vaya a ser efectiva dicha causal.

No obstante, es importante mencionar que una vez determinado el significado teórico de la edad de retiro forzoso como causal de desvinculación y el significado práctico de la relevancia absoluta del derecho fundamental al mínimo vital, es posible establecer el valor metodológico de la respuesta a la pregunta de investigación, como fundamento práctico de la solución al problema.

Así las cosas, y a partir del desarrollo del proceso de investigación científica realizado, es imperante la necesidad de desplazar la legalidad de la Ley 1821 de 2016, que se posiciona como el nuevo ordenamiento dispositivo de la edad de retiro forzoso como causal de desvinculación del servicio, con ocasión a la salvaguarda del derecho fundamental al mínimo vital del servidor que pretende ser retirado, en virtud de sus condiciones particulares.

Dicho lo anterior, es posible mencionar que la contribución de esta investigación versa sobre la proporción de una mayor comprensión de la dimensión jurídica del problema, haciendo viable el estudio histórico del objeto a fin de concluir proposiciones lógicas y acordes a la dinámica jurídica más actual. 


\section{REFERENCIAS}

Castro, A. (2018). Una aproximación teórica a la obra de Arturo Valencia Zea. De la posesión y la función social de la propiedad: el gran problema jurídico del siglo xx en Colombia, revisión histórico-jurídica. Revista Via Inveniendi et Iudicandi, 13(1), 9-54. DOI: http://dx.doi.org/10.15332/ s1909-0528.2018.0001.01. Recuperado de http://revistas. usantotomas.edu.co/index.php/viei/article/view/4265/4042

Constitución Política colombiana (1991). Asamblea Nacional Constituyente, Bogotá D. C., Colombia, 6 de julio de 1991.

Decreto No 1950. (1973). Por el cual se reglamentan los Decretos Leyes 2400 y 3074 de 1968. Presidencia de la República. Diario Oficial No 33.962 de la República de Colombia, Bogotá D. E., Colombia, 24 de septiembre de 1973.

Decreto No 2277. (1979). Por el cual se adoptan normas sobre el ejercicio de la profesión docente. Presidencia de la República. Diario Oficial de la República de Colombia, Bogotá D. E., Colombia, 14 de septiembre 141979.

Decreto No 2040. (2002). Por el cual se adicionan las excepciones contempladas en el art. 121 del Decreto 1950 de 1973. Presidencia de la República. Diario Oficial No 44.936 de la República de Colombia, Bogotá D. C., Colombia, 16 de septiembre de 2002.

Decreto No 4229. (2004). Por el cual se adicionan las excepciones contempladas en el art. 121 del Decreto 1950 de 1973. Presidencia de la República. Diario Oficial No 45.764 de la República de Colombia, Bogotá D. C., Colombia, 15 de diciembre de 2004.

Decreto No 863. (2008). Por el cual se adicionan las excepciones contempladas en el art. 121 del Decreto 1950 de 1973. Presidencia de la República. Diario Oficial No 46.942 de la República de Colombia, Bogotá D. C., Colombia, 27 de marzo de 2008.

Decreto No 740. (2009). Por el cual se adicionan las excepciones contempladas en el art. 121 del Decreto 1950 de 1973. Presidencia de la República. Diario Oficial No 47.283 de la República de Colombia, Bogotá D. C., Colombia, 6 de marzo de 2009.

Decreto No 3309. (2009). Por el cual se adicionan las excepciones contempladas en el art. 121 del Decreto 1950 de 1973. Presidencia de la República. Diario Oficial No 47.460 de la República de Colombia, Bogotá D. C., Colombia, 2 de septiembre de 2009. 
Decreto No 1083. (2015). Por medio del cual se expide el Decreto Único Reglamentario del Sector de Función Pública. Presidencia de la República. Diario Oficial de la República de Colombia, Bogotá D. C., Colombia, 26 de mayo de 2015.

Decreto Ley No 2400. (1968). Por el cual se modifican las normas que regulan la administración del personal civil. Presidencia de la República. Diario Oficial No 32.625 de la República de Colombia, Bogotá D. E., 19 de septiembre de 1968.

Decreto Ley No 3074. (1968). Por el cual se modifica y adiciona el Decreto Ley 2400 de 1968. Presidencia de la República. Diario Oficial No 32.686 de la República de Colombia, Bogotá D. E., Colombia, 17 de diciembre de 1968.

Decreto Ley No 1278. (2002). Por el cual se expide el Estatuto de Profesionalización Docente. Presidencia de la República. Diario Oficial de la República de Colombia, Bogotá D. C., Colombia, 19 de junio de 2002.

Herrera, B. (2018). Derechos de los animales: la legislación nacional interna como barrera legal para el reconocimiento de la subjetividad jurídica animal. Revista Via Inveniendi et Iudicandi, 13(1), 55-93. DOI: http://dx.doi. org/10.15332/s1909-0528.2018.0001.02. Recuperado de http://revistas.usantotomas.edu.co/index.php/viei/article/view/4266/4043

Ley No 65. (1967). Por la cual se reviste al Presidente de la República de facultades extraordinarias. Diario Oficial No 32.397 de la República de Colombia, Bogotá, Colombia, 28 de diciembre de 1967.

Ley $\mathrm{N}^{\circ}$ 344. (1996). Por la cual se dictan normas tendientes a la racionalización del gasto público y se conceden unas facultades extraordinarias. Diario Oficial No 42.951 de la República de Colombia, Bogotá D. C., Colombia, 27 de diciembre de 1996.

Ley No 797. (2003). Por la cual se reforman algunas disposiciones del Sistema General de Pensiones previsto en la Ley 100 de 1993. Diario Oficial No 45.079 de la República de Colombia, Bogotá D. C., Colombia, enero 29 de 2003.

Ley No 812. (2003). Por la cual se aprueba el Plan Nacional de Desarrollo 2003-2006, hacia un Estado Comunitario. Diario Oficial No 45.231 de la República de Colombia, Bogotá D. C., 26 de junio de 2003.

Ley No 909. (2004). Por el cual se expiden normas que regulan el empleo público, la carrera administrativa y gerencia pública. Diario Oficial No 45.680 de la República de Colombia, Bogotá D. C., Colombia, 23 de septiembre de 2004. 
Ley No 1821. (2016). Por medio de la cual se modifica la edad máxima para el retiro forzoso de las personas que desempeñan funciones públicas. Diario Oficial de la República de Colombia, Bogotá D. C., Colombia, 30 de diciembre de 2016.

Sentencia C-351. (1995). Corte Constitucional de la República de Colombia. (Exp. D-828). M. P. Vladimiro Naranjo Mesa, 9 de agosto de 1995.

Sentencia C-1037. (2003). Corte Constitucional de la República de Colombia. Sala plena. (Exp. D-4590). M. P. Jaime Araújo Rentería, 5 de noviembre de 2003.

Sentencia C-501. (2005). Corte Constitucional de la República de Colombia. Sala plena. (Exps. D-5440, D-5449 y D-5462). M. P. Manuel José Cepeda Espinosa, 17 de mayo de 2005.

Sentencia T-012. (2009). Corte Constitucional de la República de Colombia. Sala cuarta de revisión. (Exp. T-1.978.037). M. P. Rodrigo Escobar Gil, 19 de enero 19 de 2009.

Sentencia T-865. (2009). Corte Constitucional de la República de Colombia. Sala novena de revisión. (Exp. T-2353303). M. P. Jorge Iván Palacio Palacio, 27 de noviembre de 2009.

Sentencia T-007. (2010). Corte Constitucional de la República de Colombia. Sala séptima de revisión. (Exp. T-2.396.068). M. P. Jorge Ignacio Pretelt Chaljub, 14 de enero de 2010 .

Sentencia T-487. (2010). Corte Constitucional de la República de Colombia. Sala tercera de revisión. (Exps. T-2534463 y T-2534790). M. P. Juan Carlos Henao Pérez, 16 de junio de 2010 .

Sentencia T-154. (2012). Corte Constitucional de la República de Colombia. Sala novena de revisión. (Exp. T-3235947). M. P. Luis Ernesto Vargas Silva, 2 de marzo de 2012.

Sentencia T-174. (2012). Corte Constitucional de la República de Colombia. Sala primera de revisión. (Exp. T-2984795). M. P. María Victoria Calle Correa, 8 de marzo de 2012.

Sentencia T-839. (2012). Corte Constitucional de la República de Colombia. Sala primera de revisión. (Exp. T-3505035). M. P. María Victoria Calle Correa, 23 de octubre de 2012.

Sentencia T-822. (2014). Corte Constitucional de la República de Colombia. Sala tercera de revisión. (Exp.T-4.356.266). M. P. Luis Guillermo Guerrero Pérez, 5 de noviembre de 2014 
Sentencia T-643. (2015). Corte Constitucional de la República de Colombia. Sala tercera de revisión. (Exp. T-4.963.569). M. P. Luis Guillermo Guerrero Pérez, 9 de octubre de 2015 .

Sentencia T-376. (2016). Corte Constitucional de la República de Colombia. Sala tercera de revisión. (Exp. T-5.445.224). M. P. Alejandro Linares Cantillo, 15 de julio de 2016.

Suárez, C. (2018). Incidencia de la potestad del Procurador para dar muerte política a un funcionario electo por voto popular. Revista Via Inveniendi et Iudicandi, 13(1), 141-167. DOI: http://dx.doi.org/10.15332/ s1909-0528.2018.0001.05. Recuperado de http:// revistas.usantotomas.edu.co/index.php/viei/article/view/4269/4046

Suárez, M., y Vallejo, C. (2017). Las medidas cautelares innominadas y el activismo judicial. Revista IUSTA, 1(46), 139-158. DOI: http://dx.doi.org/10.15332/s19000448.2017.0046.06. Recuperado de http://revistas.usta.edu.co/index.php/iusta/article/ view/3529/3419 